\title{
La dimensón estética y semiótica en el diseño y su vínculo con el territorrio social
}

Claudio Cortés López ${ }^{(1)}$

\begin{abstract}
Resumen: Para que pueda existir un vínculo de la dimensión estética y semiótica del diseño con el territorio social lo primero que se debe realizar es una educación estética y semiótica del diseñador que es el productor del objeto de diseño; con ello se puede aspirar a que este vínculo sea efectivo y no sólo una cuestión teórica entendiendo que el producto del diseño es un objeto gráfico o industrial, dicho objeto es interpretado por un usuario determinado. Este artículo explora desde una reflexión teórica este fenómeno y pretende esclarecer desde una perspectiva ontológica, estética y semiótica la relación existente entre objeto de diseño en el territorio social y usuario. El problema que se plantea en todo lo anterior es la necesidad de una formación reflexiva en los aprendices de diseñadores que conduzca más bien a una episteme del reflexionar, más que a una doxa o vía de la opinión
\end{abstract}

Palabras clave: estética filosófica - estética fenomenológica.

[Resúmenes en inglés y portugués en la página 160]

(1) Dr. (c) Claudio Cortés López, Licenciado en Bellas Artes de la Universidad de Chile, Magíster en Teoría e Historia del Arte. Académico e investigador del Departamento de Diseño, profesor de la cátedra de Semiótica de la Imagen, Teoría de la Comunicación, y del Magíster en intervención patrimonial de Arquitectura, con la cátedra Restauración de Bienes Muebles en escuela de posgrado. Facultad de Arquitectura y Urbanismo Universidad de Chile. Consultor del Ministerio de obras públicas para recuperación y análisis del patrimonio construido mueble e inmueble, contratista en restauración para los murales del metro de Santiago de Chile, conferencista, miembro de la asociación chilena de Semiótica, articulista periódico digital "La ventana ciudadana.cl". Co-investigador fondecyt desde 1979 a 2019 con 7 proyectos; se agregan 15 proyectos de ejecución realizados con fondos de la ley de donaciones culturales. 


\section{Desarrollo}

La primera aclaratoria de este artículo corresponde a determinar la procedencia del marco teórico en términos de glosarios epistemológicos autores, y obras, la palabra estética es empleada en este artículo desde su origen epistemológico el cual proviene del término griego aisthesis este último relacionado con otras dos palabras griegas que son: aisthanomai y aisthanestai, las cuales a su vez significan "órganos de los sentidos" como también, "lo que es concebido por los sentidos" . Además, la estética que se menciona en este documento es de tradición filosófica ${ }^{2}$ es decir estéticas desarrolladas por autores como Max Bense, autor que será mencionado en repetidas oportunidades en este artículo. Con respecto a la etimología de estética se debe agregar que aisthesis proviene y precede del antiguo verbo "aio" (sentir), de acuerdo con todo lo anterior el desarrollo de la estética moderna a partir de E. Kant (crítica del juicio) y de W. F. Hegel (Estética) y otros filósofos posteriores posee tres grandes áreas de ejercicio las cuales interesan profundamente de acuerdo con el título de este artículo, estas áreas son: 1.- estética de la producción, 2.- estética de la presentación o circulación, y 3.- estética de la recepción, en cada caso hay producción teórica publicada, de relevancia, sobre todo en la no3.

Con respecto a la educación estética del diseñador, la cual involucra las tres áreas antes señaladas, mi recomendación es que los contenidos educacionales y formativos deben ser tratados por medio de un currículo de colección inserto en la malla curricular en tres semestres, he escogido el currículo de colección por las siguientes razones:

1. El currículo de colección según Wasil Bernstein, (consta de las siguientes características las cuales ofrecen un desarrollo sistemático de las materias a enseñar;

1.1. Se organiza en disciplinas curriculares bien definidas y clasificadas e independientes (Madgenzo, 2008, p. 149).

1.2. Las disciplinas o áreas del conocimiento en las que se organiza el currículum de colección se constituyen en campos de formación que aportan sus conceptos, métodos, procedimientos, epistemologías y términos en la definición de sus discursos y sus prácticas. Cada campo tiene sus propios límites, sus formas de lenguaje, sus técnicas que elabora o utiliza (Díaz, 2002a, p. 74; citado por Madgenzo, 2008, p. 149).

1.3. Según Madgenzo:

Se sostiene que el currículum de colección, al clasificar y regular fuertemente el qué de lo que se transmitirá, al establecer su ordenamiento y jerarquización está asegurando no solo el control del conocimiento, sino que también asegura, una distribución equitativa y universal del conocimiento, lo que se vincula estrechamente con la equidad con calidad del currículum (2008, p. 148).

Éstas y otras razones que se derivan de ello me llevan a afirmar que el diseño operativo para una educación estética y semiótica del diseñador debe se por medio de un currículo de colección en sus áreas de estética de la producción, estética de la circulación o presentación, y estética de la recepción, todo ello en un tiempo de tres semestres lectivos, o dos años en un magister con un total de120 horas pedagógicas como mínimo. 
La disciplina de Semiótica involucrada en el título de este artículo corresponde a la semiótica de tradición filosófica específicamente la línea de pensamiento creada por el científico y filósofo de Harvard Charles S. Peirce (1838-1914) y distribuida a lo largo de sus Collected Papers. Esta línea de pensamiento semiótico fue prolongada y dada a conocer por el científico y esteta alemán Max Bense y su equipo de trabajo en el Instituto de Filosofía de la ciencia de la U. de Stuttgart a principios de los años setenta. Esta semiótica bajo ningún punto de vista puede confundirse con la semiología de tradición lingüística ya que sus metodologías y prácticas teoréticas son diferentes lo mismo que su glosario epistemológico en torno al signo.

¿Entonces, cuáles debieran ser los saberes que un diseñador debe poseer en términos teóricos para que su objeto como producto del diseño se pueda vincular con el territorio social? ¿existen esos saberes en las mallas curriculares en la actualidad?, al parecer no dado a que hoy en día todo aquello asociado a los asuntos teóricos, especialmente dados en disciplinas como la estética y la semiótica, son considerados inapropiados, las universidades públicas y privadas privilegian en sus currículos el hacer al reflexionar, este hacer según Lyotard "saca a plena luz las funciones pragmáticas del saber puesto que ellas parecen colocarse bajo el criterio de eficiencia: pragmáticas de la argumentación, de la administración de la prueba, de la transmisión de lo conocido, del aprendizaje a imaginar" (Lyotard, 1987, p. 112). También el autor considera que en esta era post-moderna, hay una decadencia del meta relato. Y todo acontecer teórico no es un asunto de necesidad académica, la lectura de textos por parte de los estudiantes es algo poco usual incluso preguntan a un profesor si en su asignatura ¿hay que leer mucho? Las bibliografías obligatorias y complementarias tienden a desaparecer de los diseños curriculares, las cuales son sustituidas por videos tutoriales y otros de fácil digestión intelectual.

Creo que las siguientes preguntas de pueden ser naturaleza ontológica y fenomenológica pueden ser apropiadas para comenzar un estudio más o menos acabado del problema planteado en este artículo estas son:

1.1. ¿Cómo es la causa material o aquello de que el objeto de diseño debiera este hecho para que se vincule con el territorio social?

1.2. De que se trata a la causa formal o aquello que la producción del objeto de diseño es para que este último se vincule con el territorio social?

1.3. ¿Cómo es la causa eficiente o aquello que ha producido el objeto de diseño vinculado con el territorio social?

1.4. ¿De que se trata la causa final o aquello para lo que existe el objeto de diseño vinculado con el territorio social?

La hipótesis que plantea este artículo es: "La estética y la semiótica, ambas entendidas al interior de la tradición filosófica forman en su interacción una importante herramienta epistemológica para reflexionar en torno al diseño y el vínculo que debiera tener con el territorio social, y al mismo tiempo permite dar respuesta a las cuatro interrogantes ontológicas planteadas con antelación". 
El marco teórico de este artículo se encuentra señalado en los diferentes párrafos y está compuesto por autores como: Peirce, Bense, Putnam, Morris que aportan relevantes ideas y glosarios.

Se entienden como herramientas epistemológicas dado al importante repertorio argumentativo, glosario y definiciones que ambas disciplinas poseen y han aportado a través de sus diccionarios, obras y autores.

A partir de lo anterior y desde una perspectiva de la semiótica analítica y la estética fenomenológica el objeto de diseño (gráfico y/o industrial) puede o debe reconocerse como un objeto que posee un programa iconográfico por medio del cual es reconocido, leído e interpretado.

\section{Dicho programa:}

1. Nace como un acto intencional de diseño y es creado por el diseñador y al mismo tiempo le otorga al objeto de diseño su naturaleza, física, sentido, configuración y apariencia, este programa provoca una actividad Hermenéutica el en sujeto que lo percibe; hermenéutica compuesta fundamentalmente por una actividad de lectura y descodificación.

2. El programa iconográfico de la imagen que emite el objeto de diseño se encuentra compuesto por conjuntos de signos visuales dispuestos de tal forma que dicho objeto presenta interés sintáctico, semántico y pragmático ${ }^{3}$. Y puede ser estudiado desde estas tres dimensiones.

3. Este programa iconográfico posee en su íntima naturaleza elementos constructivossintácticos en varios niveles los cuales permiten su lectura y

4. Los signos visuales del programa iconográfico en su naturaleza íntima están compuestos. Por la dualidad: Intención y extensión ${ }^{4}$, la intención tiene que ver con el propósito y la extensión con la magnitud del signo en su ocupación espacial al interior del signo dado en el programa iconográfico adscrito al objeto de diseño.

Desde la estética fenomenológica planteada por Max Bense ${ }^{5}$ los siguientes términos pueden ser de utilidad al propósito de este artículo:

1. Estética material: según Bense (1969, p. 87) la situación material real de los objetos artísticos (o del diseño), en los que se puede hacer una distinción entre el portador y el estado estético y el estado estético justifica que se hable de una estética material. La estética abstracta, que es aplicable, incluye una estética material. Con ello se expresa que los estados estéticos, sólo pueden discutirse con estados materiales, o sea que sólo pueden crearse mediante la manipulación de materiales preexistentes.

2. Repertorio estético. Según Bense $(1969$, p. 88) los materiales no tienen que ser forzosamente, materiales en el sentido físico. También significados, palabras, ficciones pueden ser portadores de estados estéticos. Podría perfectamente hacerse una distinción entre materiales o portadores de estados estéticos materiales o inmateriales. Por lo general, la expresión material se entiende en el sentido de elementos diferenciables, discretos, manipulables, se llama repertorio. Los estados estéticos dependen del repertorio. Un repertorio 
estético es un repertorio material, a partir puede crearse un estado estético material correspondiente.

3. Distribución estética: a decir de Bense (1969, p. 89) las distribuciones estéticas son, pues, en primer lugar, las distribuciones por lo menos ligeramente determinadas, y en segundo lugar las distribuciones materiales. Como distribuciones materiales, son reparticiones y composiciones extensionales en esquemas espacio temporales. Las distribuciones de elementos materiales en esquemas espacio temporales pueden denominarse composiciones. Conforme a la terminología de Lessing en el Laoconte ${ }^{6}$ deben separarse las distribuciones "coexistentes" o composiciones en esquemas de espacio(pintura), de las composiciones "consecutivas" o composiciones en esquemas temporales (música, poesía). Comentario: desde estos puntos de vista las producciones del diseño gráfico debieran pertenecer a composiciones de espacio aclarando que se trata del espacio bidimensional, salvo la envaseología que es de tres dimensiones lo mismo que la arquitectura y los objetos que son producto del diseño industrial.

4. Información estética. Por información estética, Bense indica que toda información se considera dependiente del repertorio, comentario y cuestionamiento: ¿cuál es el repertorio que presenta el territorio social y como este repertorio provee de información al usuario, es este territorio una composición coexistente o consecutiva? ¿Sea como sea lo que interesa desde el punto de vista del diseño y del diseñador? Es: ¿cómo es la distribución material, se encuentra determinada? Si es así: ¿cómo el diseñador ocupa esta información para la planificación de un territorio social específico?

Las ideas de Bense sobre la estética material aporta los saberes sobre la situación real de los objetos, en este caso, la situación el objeto de diseño en cuanto a su vínculo con el territorio social. Por su lado el repertorio estético propuesto por Bense nos aporta las ideas sobre la expresión material entendida como los elementos diferenciables, discretos manipulables inserto en conjuntos a manera de signos visuales que dan forma a un programa iconográfico, si un repertorio estético, es un repertorio material según el autor.

Del cual puede crearse un estado estético material correspondiente; si el territorio social se encuentra compuesto por intérpretes, aquellos intérpretes serán quienes experimenten el estado estético material. Por su lado la distribución estética, Bense la entiende como distribuciones por lo menos ligeramente determinadas y como distribuciones materiales entendidas de esta forma el esteta alemán afirmó: " como distribuciones materiales, son reparticiones y composiciones extensionales en esquemas espacio-temporales"(1973, p. 89) con respecto a la información estética, toda información se considera dependiente del repertorio; creo que con estas ideas y otras de esta naturaleza pueden construirse respuestas epistémicas a las cuatro interrogantes ontológicas planteadas con antelación.

Desde el punto de vista de una estética nuclear, entendiendo según Bense a esta última como:

Aquella estética que trata de las unidades mínimas o extremadamente pequeñas de distribuciones sobre un repertorio de elementos materiales y de sus 
procedimientos creativos. En principio se puede considerar al repertorio como una distribución equiprobable de los elementos materiales, y esta distribución equiprobable justifica el que se diga que el estado del repertorio es caógeno. La selección de este repertorio caógeno lleva a dos estados límite estéticos: $1^{\circ}$ el orden regular del estado estructural y el orden irregular del estado configurativo (Bense, 1969, p. 97).

Ante toda esta argumentación es bueno preguntarse si el territorio social puede tener o producirse un estado caógeno, si es así debiera existir un estado estructural del territorio social, así como también un estado configurativo. Tras todo ello se encuentra una conciencia que interpreta, la de un sujeto, que vive e interpreta los signos del territorio social, entonces: ¿Cuáles son estos signos y de que clase: signos, íconos o símbolos en una trazabilidad coexistente como "estado estético" entendido a decir de Bense:

Como el estado relativamente extremo y objetivo de todos los objetos y acontecimientos a considerar, de procedencia más o menos artística, según el autor el estado estético no queda determinado como ideal, sino como realidad; se puede observar y describir como un estado real del objeto contemplado.

Si entendemos el territorio social como un objeto con una determinada constitución y con un repertorio finito de componentes en una organización no caógena, entonces podríamos determinar el estado de su estructura formada por componentes que debieran ser observables, medibles y cuantificables, dichos componentes deberían tener una sintaxis constructiva y conectores lógicos que ligan los componentes, es decir una situación material portadora e insinuadora de estados estéticos como acontecimiento real, recordemos a Bense cuando afirmó que el estado estético no queda determinado como ideal sino como un estado real del objeto contemplado que posee un repertorio con elementos diferenciables, discretos, manipulables de los cuales puede emerger una "semiosis" entendida por Bense (1969, p. 92) como:

Los procesos, los procedimientos que están ligados a signos, que se basan por lo tanto en la manipulación de signos, según el autor los fenómenos creativos y comunicativos portadores del proceso creador; los signos según el autor forman evidentemente un medio de acontecimientos y constelaciones ligeramente determinadas.

El territorio social puede considerarse un objeto cuyo estudio debiera determinar los siguientes asuntos: $1^{\circ}$ su morfología, repertorio existente en esa morfología, las relaciones sintácticas de los elementos del repertorio, el origen de sus distribuciones materiales y las semiosis relacionales que emergen de su interpretación. Con todo ello el diseñador y el diseño puede aportar sus productos.

Los procesos estéticos son reversibles, la acción creadora produce orden, clasificación, lo que disminuye la uniformidad en el sistema; por lo tanto, el grado 
de probabilidad -que aumenta en física con el aumento de la entropía- disminuye también por la acción estética el aumento del orden, la presencia de agrupaciones heterogéneas, en el dominio estético se califica como entropía negativa o neg-entropía (Schultz, revista de filosofía, p. 15).

\section{Notas}

1. Ello según el prof. Luis Advis académico de estética de la Facultad de Bellas Artes, U. de Chile 1972.

2. Hago esta aclaratoria dado a que existen estéticas sociológicas y antropológicas y de otras naturalezas, las cuales aclaran poco o nada sobre la percepción estética, o lo que la estética involucra.

3. Estas corresponden a las 3 dimensiones propuestas por Charles Morris en su obra "Fundamento de la teoría de los signos" escrita en 1938, y publicada en castellano por Paidós comunicación en 1994.

4. He tomado estos dos términos del matemático y filósofo de Harvard Hilary Putnam de su texto "significado de significado".

5. "Pequeña estética abstracta”, U. de Stuttgart trd. Andreas Faber.

6. Max Bense en este seccional hace referencia a Gothold Ephrain Lessing, un relevante Esteta alemán (1729-1781). El "Laoconte" de (1766), es un tratado sobre los límites de la pintura y de la poesía, con aclaraciones incidentales sobre diferentes puntos de la historia antigua del arte, Lessing en esta importante obra para la ilustración alemana incluyó un breve diccionario de pintores y escultores de la antigua Grecia, se debe recordar que en la ilustración alemana del siglo XVIII la admiración por la antigüedad greco latina fue enorme, los trabajos de Johan Joackim Winckelmann y Lessing colaboran al enriquecimiento de la cultura alemana en estas relevantes materias históricas y estéticas.

\section{Bibliografía mencionada}

Bense, M. (1975). La Semiótica, Guía alfabética. Barcelona: ed. Anagrama.

Bense, M. (1969). Breve Estética Abstracta. Ed. Universidad de Stuttgart.

Lyotard, J. F (1987). La condición postmoderna. Ed. Cátedra.

Madgenzo, A. (2008). Dilemas del currículum y la pedagogía. Ed. Lom.

Morris, CH. (1994). Fundamento de la teoría de los signos. Ed. Paidós comunicación.

Peirce, Ch. (2012).Obra filosófica reunida tomos 1 y 2. Fondo Cultura Económica México. 


\begin{abstract}
In order for there to be a link between the aesthetic and semiotic dimension of design with the social territory, the first thing that must be done is an aesthetic and semiotic education of the designer who is the producer of the design object; With this it is possible to aspire for this link to be effective and not just a theoretical question, understanding that the design product is a graphic or industrial object, said object is interpreted by a user.

Determined, this article explores this phenomenon from a theoretical reflection and aims to clarify from an ontological, aesthetic and semiotic perspective the relationship between the design object in the social territory and the user. The problem that arises in all of the above is the need for a reflective training in designer apprentices that leads rather to an episteme of reflecting, rather than to a doxá or way of opinion.
\end{abstract}

Keywords: philosophical aesthetic - phenomenological aesthetics.

Resumo: Para que haja uma ligação entre a dimensão estética e semiótica do design com o território social, a primeira coisa que deve ser feita é uma formação estética e semiótica do designer que é o produtor do objeto de design. Com isso, é possível aspirar a que esse vínculo seja efetivo e não apenas uma questão teórica, entendendo que o produto de design é um objeto gráfico ou industrial, que é interpretado por um usuário específico. Este artigo explora, a partir de uma reflexão teórica, esse fenômeno e visa esclarecer sob uma perspectiva ontológica, estética e semiótica a relação entre o objeto de design no território social e o usuário. O problema que surge é a necessidade de uma formação reflexiva nos aprendizes de designer, o que leva mais a uma episteme de reflexão do que a uma doxa ou forma de opinião.

Palavras chave: estética filosófica - estética fenomenológica.

[Las traducciones de los abstracts fueron supervisadas por el autor de cada artículo] 